\title{
LEIBNIZ AND THE PLURALITY OF SPACE-TIME FRAMEWORKS
}

\author{
by Nicholas Rescher
}

INTRODUCTION

Leibniz advocated a theory of space (and time) as "relative"-that is, as relative to the physical things ordinarily said to be located within space (and time). He opposed the teaching of Newton's Principia, which casts space and time in the role of containers existing on their own and having a make-up that is indifferent to the things emplaced in them. Owing to the general tenor of his theory, Leibniz is sometimes seen as a precursor of Einstein and modern relativity theory. But this view is mistaken or, at any rate, misleading. For Leibniz-unlike Einstein and the modern relativists - is not thinking of the relativity of dynamical principles to the choice of a coordinate system within nature, so that we compare the situation from the perspective of various world-included frameworks. Rather, Leibniz's thesis that "space is relative to the things in it" has regard to the perspective of various alternative possible worlds taken as a whole. The mutual attunement of whatever is included in a common world is the foundation for space and time, which have no existence apart from the concordance of the mutual "perceptions" of substances (in Leibniz's sense of this term). "[T]here is no spatial or absolute distance or propinquity of substances [monads], and to say that they are compressed in a point, or disseminated in space, is to make use of certain fictions of our spirit."

As Leibniz saw it, the Newtonian theory of "absolute" space envisages this space as an entity in its own right, a content-indifferent container which could be filled up with different substantive content in the case of different possible worlds. His own theory that space is itself something content-relative implies - by way of contrast - that every possible world must have its own characteristic spatial structure. The issue comes down to a metaphysical-rather than physical-concern. For in physics we study this world alone, whereas the point at issue is the question: Do different "possible worlds" have their own

Nicholas Rescher is University Professor of Philosophy at the University of Pittsburgh. 
spatiotemporal structure or should they be conceptualized as different ways of filling up one single common content-indifferent space-time container?

\section{Spatiality: The Conception of Space as Everywhere the Same.}

To begin with, let us recognize that the idea or conception of space must (for Leibniz) be uniformly one and the same with respect to all possible worlds. This is true for space as it is for any and every concept. A possible world may or may not contain men, and its intelligent creatures may be very different from ours, but it cannot alter what humanity is. (The concept of humanity may not find application in some other possible world, but it cannot undergo alteration there.) In every world-setting, space answers to the same conception-it is "the order of coexistence"(not-be it noted-the order of coexistents, which, after all, will differ from world to world). For Leibniz, every concept is what it is with respect to any and every possible world-the concept of space included. The concept of spatiality is worlduniform because it is world-indifferent. In this regard these concepts of space and time operate in exactly the same fashion as any concept whatsoever.

Consider the matter from another point of view, however.

\section{One World, One Space.}

The ancient atomists had an interesting theory of possibility. Confronted with a question like "Why do horses not have horns, as cows do," they responded: "The hornlessness of horses is just a local idiosyncracy of our world - our own particular environing neighborhood in the universe. Somewhere else in the infinite vastness of space there is another world, otherwise just like ours, in which horses do have horns." The atomists thus envisaged space as one vast framework in which all possibilities are concurrently encompassed.

Did Leibniz hold a view of this nature? Was space for him one vast, allcomprehensive matrix that embraced the actual and possible alike-a superspace embracing all possible worlds along with our own, actual world?

Surely not. For Leibniz, every world has its own space. There is no superspace in which distinct possible worlds are co-located with one another. Leibniz, as we may say, was a "one-world, one-space" theorist.

A space for Leibniz is an order of coexisting substances, and distinct individuals in distinct worlds do not coexist with one another. (Coexisting substances are a fortiori compossible.) There are as many such orders as there are families of compossibilia. The limits of a space are coordinate with the realm of the substances comprising its correlative world.

If Leibniz had defined space as the order of possible existents at largerather than as the order of possible $\mathrm{co}$-existents - then, to be sure, there would be only one single, all-comprehensive space. For it is clear that different substances in different possible worlds do bear various relations to one another-the relation of difference for one thing, but also similarity (in 
various regards) and so on. But while there are cross-world relations among possible substances, there are not (as I interpret Leibniz) any cross-world spatial relations. Space is the order of coexistence, and spatial relations are confined to coexistents. Distinct worlds are spatially disjoint-or better (since disjointness is itself a spatial term) they are spatially unrelated-somewhat like the dream-worlds of different people, as Leibniz himself suggests.

\section{Distinct Worlds Must Have Distinct Spaces.}

The concept of spatial emplacement thus intersects with that of compossibility. From this standpoint it is tempting to ask: "How can one substance possibly contradict another if they are located in different spaces?" But to ask this is to pick up the wrong end of the stick - it is to continue to be caught in the trap of the container theory. Substances are located in different spaces because they contradict one another: A world in which people otherwise like my parents had a daughter instead of a son for their only child must be a different world from this one (thanks to compatibility considerations), and must have its own spatiotemporal structure on the basis of these differences.

In the Paris period Leibniz enunciated a position that (as I interpret him) he continued to hold throughout his life:

[T] here could exist an infinity of other spaces and worlds entirely different [from ours]. They would have no distance from us [nor other special relations to us] if the spirits inhabiting them had sensations not related to ours. Exactly as the world and the space of dreams differ from our waking world, there could even be in such a world quite different laws of motion. (Jagodinsky, p. 114)

Leibniz's teaching is that every possible world has its own space as it has its own laws. There are many spaces, even as there are many law-manifolds. To say this does not countervail against the undoubted fact that WHAT a space is, like WHAT a law is, is uniform throughout all possible worlds. The concept (or genus) is uniform even though its exemplifications (or instances) are distinct.

Thus if one confronts the thesis that, for Leibniz, "space is one and the same everywhere, for all possible worlds," one must recognize that this is so in one sense and not so in another. It is so if we take in view the concept of space, but false if we take in view the thing to which this concept applies. For while space is-everywhere-the "order of coexistence," it turns out that what this order is is necessarily different in different worlds, since different worlds contain different (and incompatible) substances and these substances internalize such differences. (A difference in substances entails a difference in their relations, which entails a difference in ordering relations.)

For Leibnizian possible worlds, then, a difference in things brings a difference in spaces in its wake, even as this difference carries with it a difference of laws. There is, in fact, a deep analogy between Leibniz's treatment of the law-system and that of the space-system of possible worlds. And 
the following passage regarding laws (from a letter to Arnauld) is one Leibniz would unquestionably apply to space as well:

Just as there is an infinity of possible worlds, so also is there an infinity of laws, paired one for one, and every possible individual of every world includes in its notion the laws of its world. (Phil. II, 40)

\section{How are Distinct Spaces Distinct?}

It is worthwhile to pose abstractly the general (and not strictly Leibnizian) issue: What exactly is the cash-value of the difference between speaking of a plurality of distinct spaces as opposed to speaking of a single all-comprehensive superspace with many distinct sectors or subspaces? And just as one is inclined to say that the reality of real physical objects resides in their locatability in one common and unified actual space, ${ }^{2}$ why could one not say that the possibility of the possible lies in its locatability in one vast and all-inclusive common and unified superspace?

The answer here turns on two (interrelated) issues: Is the so-called superspace such that

(1) the various sectors bear such fundamentally spatial relations to one another as (for example) relative proximity and distance?

(2) the various sectors are so connected with one another that one can envisage some sort of "transport" within the space along an itinerary leading from each to the others?

Clearly, if the answer to both of these questions is no-if the so-called "subspaces" are disconnected from and spatially unrelated to one another - then there is no warrant for speaking of an overarching "superspace" at all.

The pivotal point is this: A space is individuated as a single space through the mutual relatedness and connectedness of its parts, and where these elements of mutual relation and interconnection are absent, the warrant for speaking of a single space is lacking.

When these general considerations are brought to bear on the Leibnizian situation, it is clear that the spaces of distinct possible worlds are-or can be - so unrelated and disconnected as to remove all warrant for speaking of a single uniting space. The "Wonderland" of Lewis Carroll's Alice, the "Land of Oz." of L. Baum's stories, and the "Planet Zeta" world of the Dr. Who adventures (taken as approximate examples of Leibnizian worlds) are sufficiently devoid of spatial connections and relations with one another that there is no warrant for taking them as distinct sectors of a single spatial matrix. ${ }^{3}$

Different spaces cannot form parts of a unifying superspace because they must be fundamentally disjoint - not only in a physical but even in an intellectual sense. In his extremely interesting meditation "On Existence, Dreams, and Space," Leibniz writes:

[S]pace [is] that which makes that many perceptions cohere with each other at the same time. ... The idea of space is, therefore, that through which, as is recognized, we separate clearly the place, and even the world, of dreams, from ours.... From this it follows further- 
more that there can be infinitely many spaces and, hence, worlds, such that between them and ours there is to be no distance. Plainly as the world and space of dreams differ from ours, so too can they have other laws of motion.... When we awake from dreams we come upon more congruences that govern bodies, but not that govern minds. ... Whoever asks whether another world, or another space, can exist is asking to this extent whether there are minds that communicate nothing to us. (Jagodinsky, p. 115)

With Leibniz, moreover, there is a special reason why there can be no such thing as a many-world embracing superspace. We know that, for Leibniz, a substance internalizes its relations to others in the property-system that constitutes its complete individual notion. Insofar as they go beyond this property-internalization, all relations are only "things of the mind," mere entia rationis whose "being" is virtual and imaginary, devoid of any real existence in its own right. ${ }^{5}$ The spatial relations among substances of the same possible world-like all other relations among them-thus have at least a derivative possibility of reality, namely that which arises through the prospect of their being realized along with their terms. But a "relationship" among the incompatible substances of different possible worlds-since they relate incompossible terms - can never have both feet together on the terra infirma of at least possible realization. It is, for Leibniz, already stretching matters to speak of spatial relations among compossibilities; to contemplate spatial relations among incompossibles would stretch the concept of spatial relatedness beyond its working limits. (As we have seen, space is "the order of coexistence," and incompossibles are such that-by their very nature-they cannot possibly coexist.)

\section{Why Distinct Spaces?}

It is quite clear why Leibniz wants to insist on the irreconcilable distinctness of the different spaces of different possible worlds. For if those worlds could be co-located within one superspace, then it would be feasible to realize all possibilities by the old atomists' device of shelving each possible world in its appropriate spot within the all-inclusive matrix. And all room for an ethics of creation-choice would now be removed. Since all that is possible is actual, we would return to the omninecessitarianism of Spinoza.

Leibniz develops this line of thought in the interesting essay "On Freedom" of 1679:

But I was pulled back from this precipice by considering those possible things which neither are nor will be nor have been. For if certain possible things never exist, existing things cannot always be necessary; otherwise it would be impossible for other things to exist in their place, and whatever never exists would therefore be impossible. For it cannot be denied that many stories, especially those we call novels, may be regarded as possible, even if they do not actually take place in this particular sequence of the universe which God has chosen-unless someone imagines that there are certain poetic regions in the infinite extent of space and time where we might see wandering over the earth King Arthur of Great Britain, Amadis of Gaul, and the fabulous Dietrich von Bern invented by the Germans. A famous philosopher of our century does not seem to have been far from such 
an opinion, for he expressly affirms somewhere that matter successively receives all the forms of which it is capable (Descartes, Principles of Philosophy, Part III, Art. 47). This opinion cannot be defended, for it would obliterate all the beauty of the universe and any real choice. (Loemker, pp. 263 ff.)

\section{A Superspace After All?}

But is there not, after all, a somewhat different basis for holding Leibniz committed to a superspace theory? For spaces-all spaces-are entia rationis (since there is no such substance as a space). And, as Leibniz sees it, the entire manifold of alternative possible worlds exist in concept in the mind of God sub ratione possibilitatis. Does not God relate the different spaces of the different possible worlds-coordinating them within one all-embracing superspace?

Surely not. The fact that the mind of God conceives the various possible space-orders no more means that they are comprehended within one superspace than does the fact that He conceives infinitely many laws mean that they are all comprehended within one superlaw (or the fact that He conceives infinitely many numbers mean that these are all parts of one supernumber).

The concept of a space arises from the conceptualization of spatial relations, and these relate the different items embraced within a common world. Spatial relations do not-and cannot-relate different possible worlds to one another spatially. And for a good reason: different Leibnizian worlds do not bear spatial relations to one another. Their "coexistence" in the mind of God is not the sort of coexistence that can give rise to a "space." As Leibniz explicitly says in the Jagodinsky passage quoted above, spaces arise out of relationships of "distance," which in turn root in the perceptions of substances, and there are no cross-world perceptions.

\section{Cross-world Spatial Comparisons.}

The contention that different possible worlds have their own spaces does, however, encounter one difficulty right away - a theoretical difficulty whose bearing is general, not bounded by a specifically Leibnizian context. For can we not in fact actually make cross-world spatial comparisons? Suppose M. Eiffel had made his tower a centimeter shorter. Clearly this diminished tower cannot be accommodated within this world of ours along with the actual tower. The world it inhabits is clearly another possible world. But surely it would still maintain various spatial relations to the things of this world: it would still be in Paris, and therefore surely closer to Rome than to Toronto.

In the Leibnizian setting, the answer here is not straightforward-it is yes-and-no.

Think of Leibniz's treatment of analogous hypotheses: the hypothesis, say, that Julius Caesar had been born normally, without requiring his mother to undergo a "caesarian" section. We know how Leibniz handles this. He insists that this variant Caesar is not identical with ours. The Principle of the Identity of Indiscernibles precludes strict identification. Only because of a general resemblance can we speak-loosely and inaccurately (popularly and without 
metaphysical strictness) —of this variant individual as "Julius Caesar"(i.e., as identical with the Julius Caesar of our world).

The situation must be viewed in a strictly analogous light with respect to space. If the Eiffel tower were a centimeter shorter it would NOT really be in Paris any longer - not, that is to say, in our actual Paris. The "Paris" in which it is located - and the "Rome" and "Toronto" to which it has spatial relations -are not those of our world, but those of another world. Thus it does not in fact have any spatial relations to the things of our actual world.

It is surely authentic Leibnizian doctrine that spatial relationships can be made only within and not across possible worlds.

This point becomes particularly telling if we recall the full scope and variety of Leibnizian possibilia. There are, to be sure, those possible substances which arise from hypotheses that modify actualia - the Adam who does not sin, the Judas who does not betray, the Caesar who does not cross the Rubicon. But not all possible substances need be variant versions of actual substances. We need not be in a position to re-identify a possible substance with any actual individual - not every hypothetical world is a roman a clef reworking of the actual one. Leibnizian possible worlds will in general differ very drastically from ours in their make-up-so drastically as to remove any basis for spatially relating their constituents and those of our world.

\section{Must the Spatial Structure of Other Worlds Be Like That of Ours?}

But even if distinct worlds have distinct spaces, will it not nevertheless be the case that the spatial structure of other worlds will be the same-or at any rate similar - to the spatial structure of ours?

There is nothing in Leibniz's philosophy that constrains him to answer this question affirmatively. Consider again the possible world whose Eiffel Tower was built a bit shorter (say because the iron founders who made the girders worked a trifle less exactingly). Its substances are in general so similar to those of our world that its spatial structure would be virtually identical with that of ours. But this is a very specialized circumstance, one that will certainly not be realized in general.

In thinking of the manifold of Leibnizian possible worlds, we must avoid any inclination to keep our imagination under too tight a rein. Possible worlds can differ from ours very drastically indeed. And worlds whose substances are radically different and behave in line with radically different laws of nature might well have a spatial structure quite different from ours. Leibniz's project of analysis situs ("topology" as we nowadays call it) actually represents an attempt to devise a theory of spatial relationships that does not involve the whole range of specific commitments of a full-blown Euclidean geometry. One may feel certain that Leibniz would have been neither surprised nor dismayed at the discovery of non-Euclidean geometries, and that he would have had no difficulty in assimilating such a diversity of spatial structures to his own theory of space. 


\section{The Important Fact That, for Leibniz, Time is Coordinate With Space.}

The analogous aspects of time can now be treated briefly. Time, for Leibniz, is conceptually coordinate with space: one could not have space in an atemporal context, nor conversely. For space is the order of co-existencethat is, the order among the mutually contemporaneous states of things; while time is the order of succession, that is, the order among the various different mutually coexisting states of things which, qua mutually coexisting, must of course have some sort of spatial structure.

A cinematographic analogy is helpful here. To be sure, Leibniz himself did not think of the matter in this naive pictorial way. But he thought of it in roughly equivalent terms - namely, in terms of mathematical analogues in the theory of real-variable functions. Plato notwithstanding, not all philosophers are mathematicians, and a pictorial approach may help to get the point across more effectively.

Take a motion picture film: the film reels, say, for "Gone With the Wind." And let us suppose that an immense jig-saw puzzle is created by the cutting up of this film - first into individual frames and then even more finely. The Leibnizian ordering problem is now a two-fold one, first to assemble all of the individual frames - the contemporaneity (or coexistence) slices that define its spatial order; and second the ordering of these contemporaneity slices into the proper sequence that defines a temporal order. For Leibniz, space and time thus stand in an inseparable co-ordination with one another in the overall ordering process that begins from the starting point of the particular states of individual substances and arrives at an all-comprehending spatiotemporal order. This coordinated symbiosis of space and time is an important aspect of Leibniz's metaphysics. For him - unlike Kant-space and time are mutually coordinate in such a way that neither is more fundamental than the other.

The factor of world-to-world variation thus enters into operation once more-but now with respect to time itself. For the temporal order need by no means be that of the present "Newtonian" world in which time (presumably) flows in the equable manner of a continuous parameter changing uniformly. A discrete time consisting of discrete discontinuous jumps, for example, is perfectly conceivable on Leibnizian principles - not, to be sure, as a condition holding in this best of possible worlds, but for one of its possible albeit suboptimal alternatives. In general, time, like space, need not be structurally uniform across possible worlds.

\section{Can a Possible World Lack Spatiotemporal Structure?}

We come finally to a rather delicate Leibnizian issue. Could a possible world lack a spatiotemporal structure altogether? Could the states of its substances be in such a whirl of "blooming, buzzing confusion" that a spacetime order is simply lacking? 
Leibniz would surely argue that this cannot be-that a world cannot lack a space-time order any more than it can lack a causal order. After all, even a chaotic arrangement is some sort of "ordering"-even a random ordering is an ordering (and a very characteristic sort of ordering at that).

In the Discourse on Metaphysics, Leibniz formulates the issue in the following terms:

God does nothing which is not orderly, and ... it is not even possible to conceive of events which are not regular. ... This is so true that not only does nothing occur in this world which is absolutely irregular, but it is even impossible to conceive of such an occurrence. Because, let us suppose for example that some one jots down a quantity of points upon a sheet of paper helter skelter. . . I say that it is possible to find a geometrical line whose concept shall be uniform and constant, that is, in accordance with a certain formula, and which line at the same time shall pass through all of those points, and in the same order in which the hand jotted them down; also ... . it is possible to find a mental equivalent, a formula or an equation common to all the points of this line by virtue of which formula the changes in the direction of the line must occur. There is no instance of a face whose contour does not form part of a geometric line and which can not be traced entire by a certain mathematical motion. But when the formula is very complex, that which conforms to it passes for irregular. Thus we may say that in whatever manner God might have created the world, it would always have been regular and in a certain order. (Discourse on Metaphysics. \$6)

To be sure, there are possible worlds so chaotic in their make-up that it would be inappropriate to characterize the relationships among the states of its substances as generating a "spatiotemporal order" as we know it, judging in terms of the continuities and regularities of our world. But to say this is to say little more than that the world with which we are familiar-the world we ourselves inhabit - is a very special one in the Leibnizian framework. It is, after all, the best possible world in a respect that puts prime emphasis on lawfulness and rational order.

In sum, then Leibniz holds that every possible world has a spatiotemporal structure of some sort-one that is as unique to and characteristic of it as the substances that constitute it and the laws that govern them.

\section{NOTES}

In this article I use the following abbreviations for references in the text. Phil. = Die philosophischen Schriften von G. W. Leibniz, ed. by C. I. Gerhardt, 7 vols. (Berlin, 1875-1890); Jagodinsky = Leibnitiana elementa philosophiae arcanae de summa rerum, ed. by I. Jagodinsky (Kazan, 1913); Loemker $=$ Gottfried Wilhelm Leibniz: Philosophical Papers and Letters, ed. and trans. by L. E. Loemker (Dordrecht, 1969). All translations into English are mine unless otherwise noted.

1. Phil., II, pp. 450-451. 
2. See Anthony Quinton, "Spaces and Times," Philosophy 37 (1962): 130-147. Compare also Norman Swartz, "Spatial Worlds and Temporal Worlds: Could There Be More Than One of Each," Ratio 17 (1975): 217-228. This discussion moots the prospect of several distinct spacetime frameworks for the real. These discussions are, however, different from our present inquiry, which in effect asks whether the space-time framework (or frameworks) for realia do or do not coincide with those for possibilia.

3. Perhaps this example involves a slight overstatement, since in each instance it was possible by some process (however mysterious) to transpose someone from our world to the imagined one.

4. This opuscule was written in Paris on April 15, 1676.

5. "There is among monads no spatial proximity or distance, strictly speaking. To say they are located at a point or distributed in space is to employ certain fictions of our mind, imagining to be so in reality that which can only be so in thought" (to Des Bosses, June 11, 1712). 